Submission ID: 43978

\title{
Big Data Technologies in Oil Exploration - Is It the Time to Change
} Intepretation Paradigm?

V.V. Kolesov* (Pangea Inc.)

\section{SUMMARY}

Shale oil\&gas development, fields development with horizontal wells and complexity of green and brown fields dramatically increase demands for high resolution and accuracy of reservoir characterization. Standard attribute analysis and acoustic inversion technologies in many cases are not able to provide necessary quality of the results.Big Data technologies enable to significantly increase the relability of the predictions and uncertainty evaluation of the reservoir parameters. To get maximal value of the tehnologies it is necessary to refuse from oversimplified interpretation approaches in favor of workflows in which exploration is represented as experiment-like research of reservoir properties with geophysical tools. 


\section{Технологии Big Data в нефтяной геологии - пора менять парадигму интерпретации?}

\section{В.В.Колесов (АО "ПАНГЕЯ")}

\section{Введение}

Разработка нетрадиционных залежей углеводородов, доминирование горизонтальных эксплуатационных скважин и усложнение геологического строения разведываемых и разрабатываемых месторождений кардинально повышают требования к детальности и точности прогнозирования резервуаров. Для сланцевых залежей не подходят традиционные преставления о геологическом строении, позволяющие с достаточной надежностью подсчитывать запасы подвижной нефти и оценивать возможные дебиты скважин. Горизонтальные скважины несут значительно меньше надежной информации о свойствах пластов, чем вертикальные и наклонные эксплуатационные скважины. В то же время ошибки в глубинах кровли и подошвы пласта, межфлюидных контактах, неоднородности и связности резервуара могут драматически повлиять на продуктивность горизонтальной скважины.

Общепринятые технологии интерпретации геофизических данных во многих случаях не обеспечивают получения требуемого результата, поскольку они основаны на упрощенных представлениях о свойствах резервуара и связях этих свойств с результатами геофизических измерений.

В петрофизике эти связи называются петрофизической моделью, представляющей из себя систему уравнений, связывающих данные ГИС со свойствами резервуара. Как правило, эти уравнения представляют из себя эмпирические зависимости с одной - двумя переменными, обоснованные исследованиями керна (при этом степень соответствия керна в лаборатории породам в пластовых условиях проверить практически невозможно), в ряде случаев частично обоснованные законами физики и подвергшиеся значительной проверке практикой нефтеразведки и нефтедобычи. Именно эта экспериментальная проверка и закрепила за широко используемыми уравнениями право на жизнь, очерчивая, хоть и весьма приблизительно, рамки их возможного использования.

Для интерпретации сейсмических данных наиболее широко применяются

о Атрибутный анализ (включая, в частности, построение структурных карт путем перехода от времен к глубинам через средние скорости)

о Акустическая инверсия, в простейшем случае основанная на сверточной модели

$$
F(t)=\int_{0}^{t} k(\tau) \cdot f(t-\tau) d \tau
$$

Рисунок 1 Формула сверточной моделию. Амплитуда $F$ сейсмического отражения описывается как свертка коэффициентов отражения $k$ и импульса f. При этом коэффициент отражения определяется контрастом акустических импедансов (произведения плотности на скорость волны в породе).

Необходимо заметить, что сверточная модель, изображенная на рисунке 1 , применима только А) для вертикальных лучей (при отклонении луча от вертикали существенный вклад в коэффициент отражения начинают вносить модули сдвига)

Б) для упругих пород (применимость для высокопористых флюидонасыщенных пород ограничена)

В) для нерассеивающих сред

Задача изучения нефтяных резервуаров усложняется объективными недостатками используемых данных, являющимися основными источниками неопределенностей в прогнозах параметров резервуара (/1/): 
- Неполнота (нехватка информации, ее непредставительность). Пример полифациальность резервуара, автоматически означающяа необходимость использования разная петрофизических моделей для разных фаций.

- Нечеткость (недостаточная разрешающая способность) и наличие ложных эффектов

- Стохастичность и зашумленность

○ случайный характер осадконакопления и заполнения ловушек,

○ случайные погрешности измерений (например, изменение поверхностных условий в точке сейсмоисточника)

К этим вызовам необходимо добавить еще

- Разномасштабность результатов исследований керна, ГИС, сейсморазведки

- Многомерность связей атрибутов с параметрами (каждый атрибут связан с несколькими параметрами)

Таким образом, изучая месторождение стандартными способами, мы вынуждены использовать

орезультаты косвенных измерений, несущие неустранимые систематические ошибки (различие условий керна пластовых и лабораторных условиях, низкое пространственное разрешение сейсмических данных и т.п.)

оупрощенные модели, связывающие параметры резервуара с измеряемые значениями (после сложной многоступенчатой обработки результатов измерений)

\section{Теория}

Для уточнения моделей резервуаров с использованием имеющихся геофизических данных необходимо

А) Расширение объема и набора ОДНОВРЕМЕННО используемой информации.

Б) Снятие ограничений, навязываемых упрощенными интерпретационными и геологическими моделями.

Для наилучшей реализации открывающихся возможностей надо отказаться от парадигмы обязательного использования упрощенных интерпретационных моделей в пользу представления о геологоразведке как эксперименте по изучению свойств резервуара геофизическими методами. Помимо подбора параметров среды, приблизительно соответствующих рассчитанным по упрощенным модельным формулам значениям неточных геофизических измерений, необходимо выполнять поиск реальных многомерных связей между параметрами среды и измерениями и последующий прогноз параметров на их основе с оценкой надежности прогноза $/ 2 /$.

Применение технологий анализа Больших Данных (Big Data) способно обеспечить существенное повышение надежности прогнозов и оценку неопределенности прогнозируемых параметров. Под технологиями Big Data (Большие Данные) обычно понимается совокупность подходов, инструментов и методов обработки и анализа разнородных больших и динамически пополняемых объёмов данных специальными методами и приёмами анализа с целью получения воспринимаемых человеком результатов. Для основных методов Big Data часто также используется термин Data mining ("раскопки данных") - поиск закономерностей в данных с использованием статистических и эвристических методов. Последний термин практически эквивалентен также понятию «Когнитивный анализ данных».

Основной источник взрывоподобного развития Big Data в современной информатике глобальный технологический вызов «необозримости» данных видеофиксации. Необходимость применения этих методов в геологии вытекает из невозможности ОДНОВРЕМЕННОГО учета - («необозримости») разнородных геофизических данных для прогноза геологических параметров.

История применения методов Big Data в нефтяной геологии насчитывает более 50 лет и началась в Советском Союзе (см., например, /3/). История показывает, что практическое применение этих методов сталкивается со следующими основными вызовами

оНеполнота обучающих выборок

оНеоднородность обучающих выборок 
○Очень сложные процедуры измерений - источника обрабатываемой информации оНеконтролируемые систематические погрешности измерений

Стандартные методы Big Data (наиболее популярны на сегодня нейронные сети) в нефтегазовой геологии из-за перечисленных выше вызовов работают не лучшим образом. Алгоритмы Big Data необходимо адаптировать и применять комплекс различных подходов, использующих разные виды данных и их комбинации.

В прогнозировании свойств резервуара $\mathrm{c}$ использованием данных сейсморазведки используются следующие группы алгоритмов, имеющие свои достоинства и недостатки

оИнверсия (с использованием импедансов) - самый популярный подход, имеющий в основе простую и наглядную модель, но испытывающий много ограничений при получении результатов

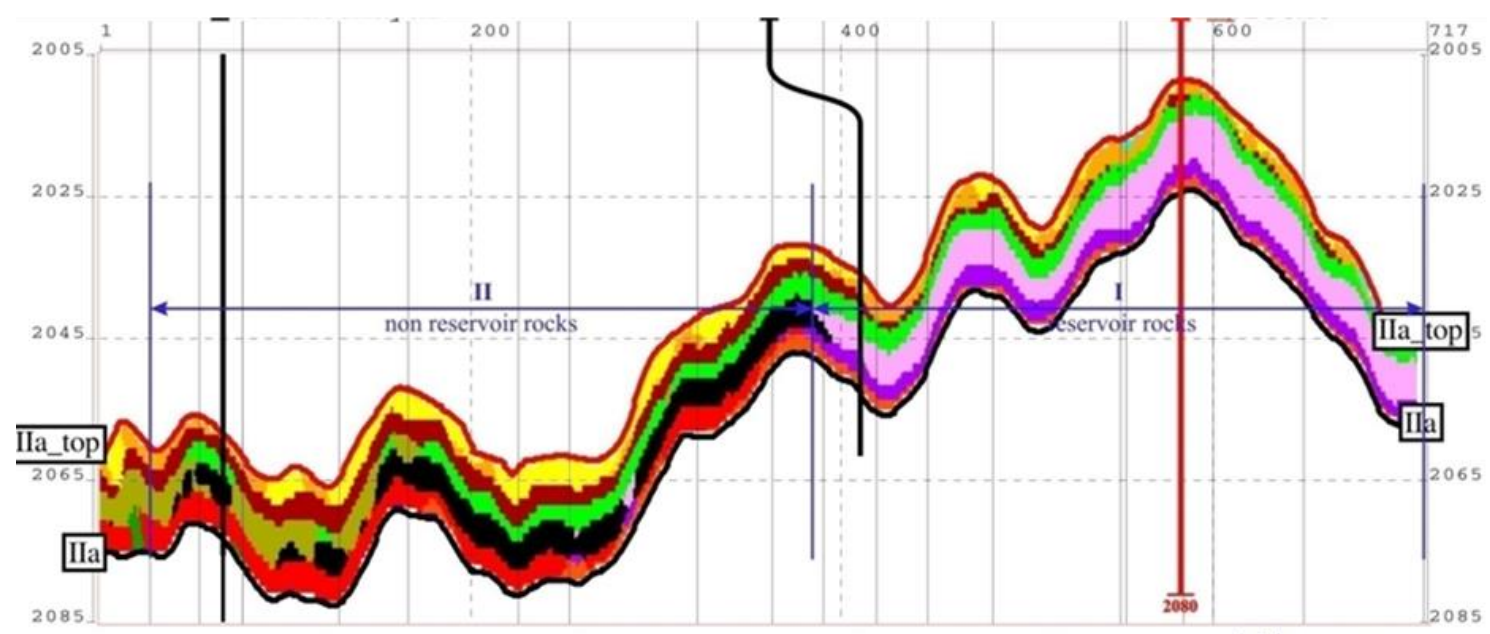

Рисунок 2 Классификаџия сейсмического разреза в интервале баженовской свиты. Розовым показан класс, развитие которого соответствует продуктивности баженовской свиты, установленной по скважинам, пробуренным в районе пикетов 400 и 600. Скважина в левой части разрез вскрыла непродуктивный разрез баженовской свиты.

оОбъемная классификация сейсмических кубов /4/ с анализом соответствия сейсмофаций литотипам и последующей генерацией куба песчанистости. Этот подход меньше других реагирует на проблемы привязки скважины к разрезу и неоднородности обучающей выборки (рис.2)

оКонверсия (мультиатрибутная инверсия) сейсмических трасс в трассы параметров с использованием каротажных данных (генерация кубов псевдокаротажа) /4/(рис.3)

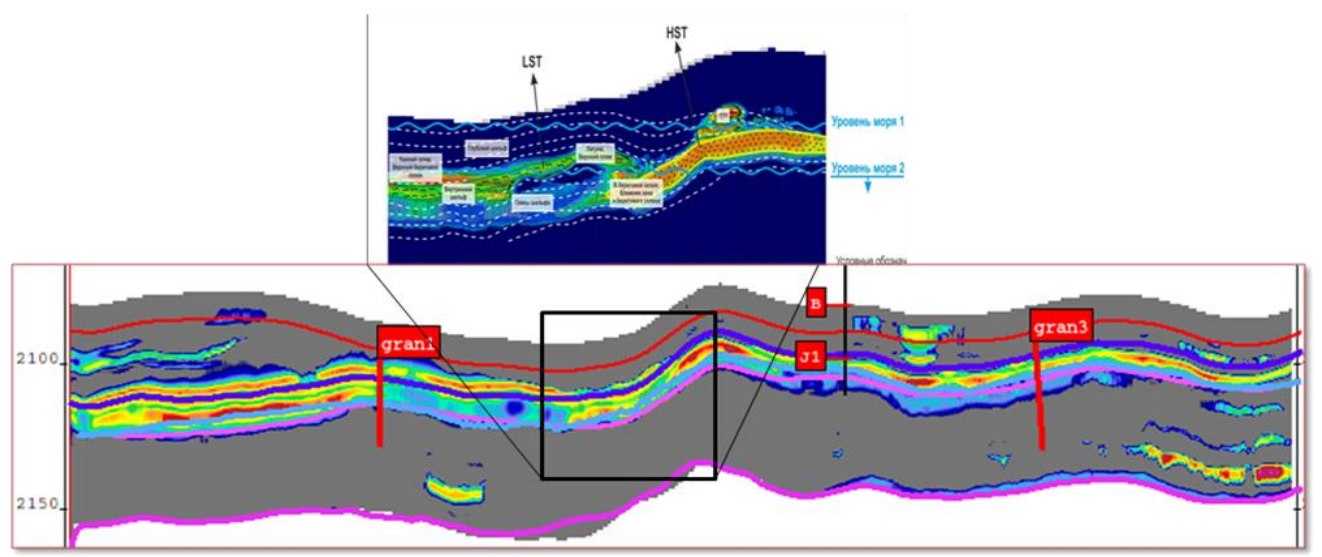


Рисунок 3 Результат конверсии сейсмического куба в куб песчанистости и конщептуальная седиментачионная модель. Мощность отдельных песчаных тел (желто-красная заливка) не превышает 6 м. Видимая на рис. разобщенность перекрывающихся в плане линз, сформированных в разных фазах эвстатических колебаний уровня моря, позволила объяснить скачок ВНК на 20 м в соседних эксплуатационных скваэсинах и существенно уточнить контуры залежей эксплуатируемого месторождения.

○Прогноз с использованием петрофизических связей между интегральными сейсмическим атрибутами и параметрами пластов (средними или максимальными/минимальными), включая построение структурных карт при большом количестве скважинных данных 15/. Подход отличает оптимальная параметризация задачи, наибольшая универсальность для прогноза свойств пласта в целом. Практически нет ограничений по мощности изучаемого пласта.

\section{Выводы}

Если стандартная последовательность хорошо понятных процедур, основанных на упрощенных представлениях (сверточная модель, парные корреляции с атрибутами и т.п.) не обеспечивают получения результата, то предлагается исследовать свойства резервуара по методике научного эксперимента, предусматривающего следующую последовательность работ

оИспользование результатов стандартных подходов в качестве входных данных (атрибутов)

оПоиск многомерных связей параметров резервуара с измеренными геофизическими характеристиками и геологической информацией методами Big Data

○ Статистическая оценка надежности этих связей

○Прогноз параметров с использованием связей, имеющих понятную физическую и геологическую природу

○Применение нескольких независимых методов для подтверждения полученных результатов

оИнтеграция полученных результатов в геологическую модель резервуара

\section{Библиография}

1. Lucy Foley, Leslie Ball, Andrew Hurst, John Davis and David Blockley. Fuzziness, incompleteness and randomness: classification of uncertainty in reservoir appraisal Petroleum Geoscience, 1997, Vol 3, No 3, pp. 203 - 209

2. Колесов В.В. Принципы технологии многомерной интерпретации. - Геофизика, 2004, специальный выпуск, стр. 7-11.

3. Элланский М.М.,Еникеев Б.Н. Использование многомерных связей в нефтегазовой геологии.-М.:Недра, 1978.

4. Гривко И.Л., Лурье М.Б. Алгоритмы безэталонной классификации и количественного прогноза. - Геофизика, 2004, специальный выпуск, стр.28-31.

5. Методические рекомендации по использованию данных сейсморазведки (2D,3D) для подсчета запасов нефти и газа.-М.:МПР РФ, ОАО ЦГЭ, 2006

\section{References}

1. Lucy Foley, Leslie Ball, Andrew Hurst, John Davis and David Blockley. Fuzziness, incompleteness and randomness: classification of uncertainty in reservoir appraisal Petroleum Geoscience, 1997, Vol 3, No 3, pp. 203 - 209

2. Kolesov V.V. Printsipy tekhnologii mnogomernoy interpretatsii. - Geofizika, 2004, spetsial'nyy vypusk, str. 7-11.

3. Ellanskiy M.M.,Yenikeyev B.N. Ispol'zovaniye mnogomernykh svyazey $\mathrm{v}$ neftegazovoy geologii.-M.:Nedra, 1978.

4. Grivko I.L., Lur'ye M.B. Algoritmy bezetalonnoy klassifikatsii i kolichestvennogo prognoza. Geofizika, 2004, spetsial'nyy vypusk, str.28-31.

5. Metodicheskiye rekomendatsii po ispol'zovaniyu dannykh seysmorazvedki (2D,3D) dlya podscheta zapasov nefti i gaza.-M.:MPR RF, OAO TSGE, 2006 